\title{
MtGox Co., Ltd (Re), 2014 ONSC 5811
}

Insights from some Canadian cases into the application of the UNCITRAL Model Law on Cross-Border Insolvency (1997) regarding the debtor's centre of main interests

\section{Introduction}

If an international model law has been adopted in two countries in reasonably similar terms, it is instructive for lawyers from the one country, who lack cases decided in terms of their local version of the model law, to consider cases decided in the other country as a source of examples and guidelines with respect to the application of that model law. MtGox Co., Ltd (Re) ('MtGox') was decided in terms of the Canadian adaptation of the UNCITRAL Model Law on Cross-Border Insolvency Law (1997) (the Model Law), which is in full force in Canada. By contrast, the South African adaptation of the Model Law in the Cross-Border Insolvency Act 24 of 2000 (the CBIA) is still not in full force in this country, because the Minister has not yet designated the states to which the statute applies (ss 2(2)-2(5)). So there are no South African precedents that can be commented on as regards the interpretation and application of this statute in practice. However, as the relevant South African crossborder insolvency provisions form part of the latest Insolvency Bill about which there is some interest (see Keynote Address by the Deputy Minister of Justice and Constitutional Development, the Hon John Jeffery MP, at the INSOL Africa Round Table (2015) available from http://www. gov.za/speeches/insol-africa-round-table-12-oct-2015-0000 (accessed 2016-10-31)), it is submitted that a consideration of the relevant crossborder insolvency provisions and then some comparisons with the equivalent Canadian provisions may prove instructive for South African lawyers, for when they do come to face interpretational issues in terms of the local provisions in practice. More particularly, in the search for a viable approach to determining the debtor's centre of main interests (COMI), as no such approach is set out in detail in the Model Law or in its 
Canadian or South African adaptations, it is submitted that a consideration of the two approaches adopted in Canadian case law may offer a fruitful ground for comparison in South African law.

Accordingly, this case note briefly summarises the relevant provisions of the South African CBIA. This sketch enables South African readers to consider the brief statement of the MtGox facts and then the Canadian application of the corresponding provisions to those facts, with respect to the recognition of foreign proceedings, the classification of those proceedings as foreign main proceedings, and the resultant automatic stay of local proceedings. After dealing with these three aspects, the discussion proceeds to deal with the two Canadian tests for determining the debtor's COMI - the three-pronged test in one line of cases, and the multifaceted approach applied in another line of earlier cases. The conclusion to this case note discusses the possible application of these two Canadian tests by South African lawyers and courts if the local statute should come into full force once the Minister promulgates the required list of countries.

For the sake of argument, it is assumed that such a list would include the countries mentioned in the Canadian cases - Canada, the United States of America, Japan, and Germany.

\section{Selected Provisions of the South African Cross-Border Insolvency Act}

A foreign representative seeking to deal with property in South Africa or receive assistance here is required to apply to the South African court for the recognition of the foreign proceedings (s 15(1)). The relevant South African definitions follow those of the Model Law. Thus, the foreign proceedings are collective judicial or administrative proceedings in a foreign state, including interim proceedings, under insolvency law in which proceedings the debtor's assets or affairs are subject to a foreign court's control or supervision, for reorganisation or liquidation (s 1 (g)). The foreign representative (including an interim appointee) is authorised in foreign proceedings to administer the reorganisation or the liquidation of the debtor's assets or affairs or to act as the representative of the foreign proceedings (s 1 (h)).

The foreign representative, as well as the South African court that is approached for recognition and assistance, must, as soon as possible (s 17(3)), draw an essential distinction between two types of foreign proceedings (s 17(2)). Foreign main proceedings are those proceedings taking place in the state where the debtor has the centre of her, his, or its main interests (s 17(2)(a)), and foreign non-main proceedings are those proceedings that are taking place in a state where the debtor has an establishment (s 17(2)(b)). An establishment is any place of operations where the debtor carries out a non-transitory economic activity with human means and goods or services (s 1(c)). 
Of the three presumptions regarding recognition (s 16), the third is the important one for present purposes. In the case of a company, unless there is proof to the contrary, the debtor's registered office is presumed to be the debtor's COMI (s 16(3); this presumption and its displacement are discussed in par 5 infra).

The recognition of foreign proceedings as foreign main proceedings has certain important effects (s 20). The first is the stay that follows upon such recognition. This immediate stay applies to the commencement or continuation of individual legal actions or legal proceedings as to the debtor's assets, rights, obligations, or liabilities (s 20(1)(a)). The stay also applies to execution against the debtor's assets (s 20(1)(b)).

The relevant South African provisions having been sketched, the discussion moves on to the facts of MtGox.

\section{The Facts of MtGox}

MtGox was registered and had its headquarters in Japan (MtGox par 3), and from April 2012 to February 2014 ran its online exchange for buying and selling bitcoins - a digital currency - on its website (http:// www.mtgox.com). When thousands of bitcoins were lost or stolen, the company stopped withdrawals from its customers' bitcoin accounts and soon suspended trading (MtGox par 4).

The court in Tokyo found that MtGox could not be rehabilitated, and it wound up MtGox and appointed Kobayashi as the trustee (MtGox parr 6-7). The company had about 120000 customers who held bitcoin or fiat currency balances and who lived in about 175 countries (MtGox par 8). A class action against MtGox was instituted in the Superior Court of Justice in Ontario (MtGox par 9; see Joyce $v$ MtGox Inc., 2016 ONSC 581 ) by Canadian residents claiming that they were 'owed currency and the value of bitcoins by Mt. Gox that they [had] been unable to withdraw' (Becker 'Canadian Class-Action Lawsuit Filed against Mt. Gox, Mizuho Bank' Reuters (2014-03-14) available from http://www.reuters.com/ article/bitcoin-mtgox-mizuho-idUSL2N0MC01G20140315 (accessed 2016-10-31); recent news is that on 17 June 2016, the court in Ontario dismissed the class action, leaving individuals to carry on with their own claims (EconoTimes 'Mt Gox Class Action Lawsuit Dismissed In Canada' EconoTimes: Digital Currency Revolution (2016-05-19) available from http://www.econotimes.com/Mt-Gox-Class-Action-Lawsuit-Dismissed-InCanada-210153 (accessed 2016-10-31))).

In October 2014, the Japanese trustee applied for initial recognition to the Superior Court of Justice in Ontario (MtGox par 1). The relevant local provisions on cross-border insolvencies were in the Bankruptcy and Insolvency Act, R.S.C 1992, c. 27, s. 2 (BIA), with its Part XIII on crossborder insolvencies comprising sections 267 to 284. The Japanese trustee sought a declaration and recognition concerning the Japanese bankruptcy proceedings, which he claimed were a foreign main proceeding (BIA s 270). He also sought a declaration that he was a foreign 
representative (BIA s 268(1)) with the right to bring this application (BIA s 269), and he sought to stay and enjoin claims, rights, liens or proceedings against or concerning MtGox and its property. The Japanese trustee gave his reasons for bringing this application as follows: he wished to maximise creditors' recoveries and seek a fair distribution of value among creditors, and so he considered it necessary to interdict the Canadian litigation against MtGox (MtGox par 25). This injunction was to operate with the protections under the Japanese bankruptcy proceeding.

\section{The Judgment of Newbould J}

\section{The Applicable Law}

Newbould $\mathrm{J}$ held that between the two extremes of territorialism and universalism (MtGox par 10), the growing impetus in multinational bankruptcies was towards modified universalism (MtGox par 11). The main proceedings involving the debtor should be recognised in court in a single jurisdiction, and proceedings in other jurisdictions should be recognised as non-main proceedings (MtGox par 11). Modified universalism underlay the Model Law, which had been mostly adopted by Canada in 2009 through amendments to the BIA and the Companies' Creditors Arrangement Act RSC 1985, c C-36 (CCAA) (as to the CCAA, cf also Caterpillar Financial Services Corporation $v$ Boale, Wood \& Company Ltd., 2014 BCCA 419 (CanLII) par 27). Even before 2009, Canadian courts had applied comity in cross-border insolvency cases (MtGox par 11; Babcock \& Wilcox Canada Ltd., (Re), 2000 CanLII 22482 (ON SC); 18 CBR (4th) 157; and Lear Canada (Re), 2009 CanLII 37931 (ON SC); (2009) 55 CBR (5th) 57 (Ont SCJ)).

\section{Recognition of Foreign Proceeding}

A foreign representative may apply for the court in Canada to recognise the foreign proceeding (MtGox par 13; BIA s 269(1)). The court must recognise the foreign proceeding if it is a foreign proceeding and the applicant is its foreign representative (BIA s 270(1)).

According to Newbould J, a 'foreign proceeding' is a judicial or administrative proceeding, including an interim one, in a jurisdiction outside Canada, and dealing with creditors' collective interests generally 'under any law relating to bankruptcy or insolvency'; and the debtor's property and affairs are controlled or supervised by a foreign court for reorganisation or liquidation (MtGox par 14; BIA s 268(1)).

As seen in paragraph 2 above, the broad South African definition of 'foreign proceedings' follows the definition in the Model Law. The beginning of the Canadian definition has a different order, and the words 'bankruptcy or insolvency' allow for variations in the name of the relevant area of law.

Newbould $J$ applied the Canadian definition to the Japanese bankruptcy proceeding (MtGox par 15). It was a judicial proceeding and 
related to the collective interests of creditors generally under the Bankruptcy Act in Japan. In terms of this Act concerning bankruptcy and insolvency, the Tokyo District Court, Twentieth Civil Division, supervised the assets of MtGox, and the Japanese proceeding thus met the definition in section 268(1) of the BIA. The Japanese proceeding would similarly meet the South African definition of foreign proceedings mentioned in paragraph 2 above.

The next question was whether the Japanese trustee was a foreign representative (BIA s 268(1); MtGox par 16). This was a person or body, including a provisional appointee, who was authorised in a foreign proceeding, as regards the debtor, to administer the debtor's property or affairs for reorganisation or liquidation, or else to act as a representative as regards the foreign proceeding. Again, the South African definition is similar, as seen in paragraph 2 above.

Newbould J applied the Canadian definition to the Japanese trustee (MtGox par 17). This person, under the Japanese bankruptcy statute and the Tokyo Court's order in the Japanese bankruptcy proceeding, was authorised to administer the property and affairs of MtGox for liquidation and act as a foreign representative. The trustee met the Canadian definition, and so the court in Canada could recognise the Japanese proceeding as a foreign proceeding (MtGox par 18). Similarly, the Japanese trustee would meet the definition in the CBIA, and therefore, as can be seen from the discussion in paragraph 2 above, the South African court would recognise the Japanese proceeding.

\section{Foreign Main Proceeding}

A distinction was drawn between a foreign main proceeding and a foreign non-main proceeding (MtGox par 19). In MtGox, the Japanese trustee sought recognition of the Japanese proceeding as a foreign main proceeding. According to Newbould J, a foreign main proceeding was a foreign proceeding in a jurisdiction where the debtor's COMI was located (BIA s 268(1); MtGox par 20). Unless there was contrary proof, the debtor company's registered office was deemed to be that centre (BIA s 268(2)). Similarly, as noted in paragraph 2 above, the South African definition of 'foreign main proceeding' must be read with the deeming provisions that - in the case of a company, unless there is contrary proof - the company's registered office is deemed to be the debtor's COMI.

Newbould J listed three factors that must be taken into account in determining the COMI (Lightsquared LP (Re), 2012 ONSC 2994 (CanLII); (2012) 92 CBR (5th) 321 (Ont SCJ); MtGox par 21). Could creditors promptly ascertain the location of that centre? Were the debtor's main assets and operations found there? And was the debtor managed there?

The Japanese trustee provided facts showing that MtGox's COMI was Japan (MtGox par 22). The trustee listed eight aspects, which may be summarised as follows. MtGox had always been organised in Japan, where its registered office and headquarters had always been located 
and its books and records kept and most of its bank accounts, including the main one for operating the business, were maintained. In Japan, its parent company, Tibanne, provided MtGox with operational and administrative services such as its main workforce. MtGox's only director at all relevant times had lived in Japan. MtGox's website clearly showed customers and others that the company was a Japanese corporation located in Japan. The company had investigated the facts that brought about the Japanese civil rehabilitation, under the Tokyo Court's supervision. The company had no offices, subsidiaries, or assets in Canada (par 22).

Newbould J concluded that the company had its COMI at its registered office in Japan (MtGox par 23). He held that the Japanese bankruptcy proceeding was a foreign main proceeding (par 23).

It is submitted that, similarly, on the grounds set out in paragraph 2 above, the South African court would find that the COMI of MtGox would be located in Japan. It is assumed for the sake of argument that there would be no offices, subsidiaries, or assets of the company in South Africa.

\section{The Stay of Proceedings}

Recognising the Japanese proceeding as a foreign main proceeding (BIA s 271(1); MtGox par 24) resulted in a general ban on instituting or continuing legal actions, execution or other proceedings related to MtGox's property, debts, liabilities or obligations (BIA s 271(1)(a)). Debtors carrying on business must not dispose of their property in Canada except in the ordinary course of business (BIA s 271(1)(b)). Individual debtors must not sell or dispose of their property in Canada (BIA s 271(1)(C)).

Japan adopted the Model Law in 2000 (MtGox par 27). Newbould J confirmed the transparent regime that the Model Law introduced foreign creditors were entitled to begin or take part in insolvency proceedings in a different state (Sarra 'Oversight and financing of crossborder business enterprise group insolvency proceedings' 2009 Texas International LJ 547). This aim was advanced by the automatic stay (BIA s 271(1)(a)). The Japanese trustee had a right to this stay because the Japanese proceeding was a foreign main proceeding. The Tokyo Court had set a final date for filing claims by 29 May 2015.

Newbould J mentioned the North American class actions against MtGox (MtGox par 28). Two of them had opened in the United States, and the Japanese trustee had obtained recognition of the Japanese proceedings as a foreign main proceeding under Chapter 15 of the United States Bankruptcy Code (hereafter Bankruptcy Code; see US Code Title 11 - Bankruptcy Chapter 15 Ancillary and other cross-border cases (ss 15011532) available from https://www.law.cornell.edu/uscode/text/11/ chapter-15; that chapter adopted the Model Law for the United States, and was added by the Bankruptcy Abuse Prevention and Consumer 
Protection Act of 2005). The United States litigation had been automatically stayed. Newbould J concluded that, similarly, the Japanese trustee had a right to the automatic stay of the Ontario class action.

On the basis of the relevant South African provisions in paragraph 2 above, it is submitted that the Japanese trustee would likewise be entitled to the automatic stay under section 20(1)(a)-(b) of the CBIA.

Having dealt with the three aspects - recognition, the classification of the proceedings as foreign main proceedings, and the stay of local proceedings - the discussion proceeds to the two Canadian tests for determining the debtor's COMI. These two tests are dealt with in paragraphs 51 and 52 below. After that, the conclusion in paragraph 6 of this case note considers the possible application of the two tests in South African law should the South African CBIA come into full force once the Minister designates the relevant states.

\section{Two Canadian Tests regarding the Determination of the Debtor's Centre of Main Interests}

This paragraph discusses the more recent three-pronged test and then the earlier, multifaceted test.

\section{The Three-pronged Test in Lightsquared}

The facts of MtGox enabled Newbould J to reach a straightforward decision in finding that the COMI of MtGox was Japan (MtGox par 23). The court dealt with the eight listed factors as a whole (MtGox par 22, items (1)-(8)) and did not provide separate answers to the three questions posed by the Lightsquared test as stated in MtGox (par 21). It would have been interesting to see the court answer these questions separately. This exercise may be carried out for the sake of argument. Firstly, as regards whether creditors could ascertain the COMI, what was significant was that the website of the company clearly showed customers and third parties that the company was a Japanese company incorporated in Japan. This website was accessible throughout the world before it was closed down. Secondly, as regards the location of the main assets and operations of the company, it was clear that most of MtGox's bank accounts, including its main business operating account, were in Japan, along with its books and records. That country was where its main workforce operated. Finally, regarding the place where MtGox was managed, the registered office coincided with the headquarters in Japan, and the sole director of MtGox lived there. Both the parent company and the company were Japanese companies. It was also interesting that the Japanese trustee added the information about the rehabilitation inquiry conducted in Japan.

The evidence provided by the Japanese trustee showed the predominance of connections to Japan, starkly contrasted by the trustee with the absence of links to Canada, where there were no offices, 
subsidiaries, or assets (MtGox par 22, item (1)). There were creditors, as the Canadian class action showed (MtGox par 9, read together with Joyce $v$ MtGox Inc. supra), but no attempt was made, so it seems, to indicate where the main creditors of the company were located. It appears that no creditor intervened to oppose the Japanese trustee's application for recognition as a foreign trustee and thus to provide evidence that Canada should be found to be the COMI.

It was important for the Japanese trustee to provide evidence, a step necessary for applying the presumption regarding the registered office of the company to the facts. It is interesting that in the absence of sufficient uncontested evidence as to the debtor's COMI, a court in Canada may be prepared to make a preliminary finding with the co-operation of the parties. Thus in Burckhardt Reimer (Re), 2012 BCSC 2091 (CanLII) par 18 there was a dispute whether the petitioner had led enough evidence to establish the COMI for the respondents to contest. Prompted by Griffin J, the parties co-operated in preparing a draft order (Burckhardt Reimer par 20). Comity was shown towards the German insolvency proceeding (Burckhardt Reimer par 21), which was provisionally recognised as a foreign non-main proceeding (BIA s 270), without prejudice to a subsequent application to establish that it was a foreign main proceeding (Burckhardt Reimer par 23).

The simplicity of the MtGox facts may be contrasted with the more complicated variations that can be found in some of the other Canadian cases on cross-border insolvency. An example of more complicated facts is the Lightsquared case itself - relied on by Newbould J for his statement of the three factors for the court to consider in determining the COMI (MtGox par 21).

In Lightsquared LP (Re), 2012 ONSC 2994 (CanLII); (2012) 92 CBR (5th) 321 (Ont SCJ), the applicant, Lightsquared LP, and some of its affiliates began voluntary reorganisation proceedings under Chapter 11 of the United States Bankruptcy Code in New York. The companies stated that they would be applying for Lightsquared LP to act as the foreign representative (Lightsquared parr 1-2). The initial recognition order sought from the Ontario Court in Canada was for a declaration of that company's status as a foreign representative, that the Chapter 11 proceeding was a foreign main proceeding under the CCAA, and that proceedings against the Chapter 11 debtors should be stayed (Lightsquared par 5). Of these twenty entities, sixteen had head offices or headquarters in the United States (Lightsquared par 8). Three of the debtors were Canadian - SkyTerra Holdings (Canada) Inc. (SkyTerra Holdings) and SkyTerra (Canada) Inc. (SkyTerra Canada), both incorporated in Ontario, and Lightsquared Corp. (LC), incorporated in Nova Scotia (Lightsquared par 9).

The Canadian debtors had the following functions (Lightsquared par 11). First, SkyTerra Canada held regulated assets as Canadian corporations were required to hold, and these assets were of mainly 
three types - a satellite, Canadian industry licences, and contracts with Lightsquared LP's affiliates and third parties. SkyTerra Canada had no third-party customers or employees, and was funded entirely by Lightsquared LP. Second, SkyTerra Holdings, lacking employees or operational functions, was only to hold SkyTerra Canada shares. Third, LC was to provide customer services in Canada with respect to products and services that the Chapter 11 debtors had created for the United States market. LC held Canadian licences and authorisations and groundrelated assets. The forty-three employees at LC's Ottawa offices did not belong to a union. Lightsquared LP funded LC's operations.

The integrated group management resulted in corporate and important decisions being taken in the consolidated offices in the United States (Lightsquared par 12). The Chapter 11 debtors' senior executives, including those of the Canadian debtors, lived in the United States. Management of the Chapter 11 debtors, including the Canadian ones, was mostly shared. For the Chapter 11 debtors, including the Canadian ones, the majority of the 'employee administration, human resource functions, marketing and communication decisions... and related functions' took place in the United States (Lightsquared par 12). Cash was managed under the supervision of employees mainly in the United States. Various other functions were shared among the Chapter 11 debtors, including the Canadian ones, and were managed mostly in the United States, such as 'pricing decisions, business development decisions, accounts payable, accounts receivable and treasury functions' (Lightsquared par 12).

Nearly all the funding of the Canadian debtors came from Lightsquared LP and other United States debtors (Lightsquared par 13). Lightsquared LP's credit facilities were guaranteed by the Canadian debtors by a priority interest over their assets (Lightsquared par 14). Accordingly, the Chapter 11 debtors' creditors were mostly common to them.

Morawetz J confirmed that, without contrary proof, the registered office of a debtor was deemed to be its COMI (Lightsquared par 23). The Canadian debtors had registered offices in Canada, but Lightsquared LP argued that Canada was not the COMI of the Canadian debtors (Lightsquared par 24).

Morawetz $\mathrm{J}$ held that if the court needed to travel beyond the presumption in section 45(2) of the CCAA regarding the registered office, 'the following principal factors, considered as a whole, [would] tend to indicate' whether the COMI was located where the proceedings were filed (Lightsquared par 25). Morawetz J then stated the list later given by Newbould J in MtGox (see par 43 supra). Morawetz J explained that these three factors would usually indicate one jurisdiction as the COMI (Lightsquared par 26). Where the factors differed, the facts would need to be examined. One factor might have to be given greater or lesser weight, depending on the facts. But the overall purpose was to ascertain 
that the location of the proceeding, in fact, corresponds to where the debtor's true seat or principal place of business actually is, consistent with the expectations of those who deal with the enterprise prior to commencement of the proceedings (Lightsquared par 26).

If the court found that the evidence contradicted the presumption, it should take the three factors into consideration when deciding where the COMI was located (Lightsquared par 27). This approach accorded with the 'preliminary commentary in the Report of UNCITRAL Working Group V (Insolvency Law) of its 41st Session (New York, 30 April - 4 May, 2012) (Working Paper AICN.9/742, paragraph 52' (Lightsquared par 28). Morawetz $\mathrm{J}$ considered this three-pronged framework appropriate for examining the COMI. He intended it to be a refinement of his opinion in Massachusetts Elephant \& Castle Group Inc. (Re), 2011 ONSC 4201; (2011) $81 \mathrm{CBR}$ (5th) 102, where he had considered the following factors to be important:

- the location of the debtor's headquarters or head office functions or nerve centre;

- the location of the debtor's management; and

- the location which significant creditors recognize as being the centre of the company's operations (Massachusetts par 30).

As Part IV of the CCAA on cross-border insolvencies did not deal with corporate groups, the COMI had to be determined for each entity (Lightsquared par 29). Morawetz J applied his revised three-pronged test to the facts, and found that the Canadian debtors' centres of main interests were in the United States (Lightsquared par 31 ).

The three-pronged test in Lightsquared and MtGox has also since been applied in Caesars Entertainment Operating Company, Inc. (Re), 2015 ONSC 712 (CanLII) par 33. In that case, Morawetz J found that the Chapter 11 debtors' COMI was the United States, where most of the other 172 Chapter 11 debtors were incorporated and headquartered and where they conducted various activities (Caesars Entertainment Operating Company par 35).

LeBlanc J also mentioned the Lightsquared three-pronged test in the Supreme Court of Nova Scotia (Wolfridge Farm Ltd. (Re), 2015 NSSC 168 (CanLII) parr 32-33). The judge held that the presumption regarding the registered office in the United States had been rebutted, and that the COMI of Wolfridge Farm Ltd was Nova Scotia (Wolfridge Farm par 55). LeBlanc J also referred to Probe Resources Ltd. (Re), 2011 BCSC 552 (CanLII); [2011] B.C.J. No. 802 (QL) parr 21-22, in which Fitzpatrick J in the Supreme Court of British Columbia had discussed work by Sarra (Rescue! The Companies' Creditors Arrangement Act (2007) 295-296) and McElcheran (Commercial Insolvency in Canada (2011) 376) to the effect that the relevant centre was where the debtor regularly administered its interests and where the creditors could ascertain this too (Wolfridge Farm par 30). On the basis of decisions from the European Union and the 
United States, it was submitted by these authors that rebutting the presumption might be based on objective factors that would lead third parties reasonably to conclude that the registered office was not the COMI. The factors might include the locations of the headquarters, the management, the main assets and operations, and most of the creditors.

The Lightsquared three-pronged test has also recently been applied by Newbould J in Zochem Inc. (Re), 2016 ONSC 958 (CanLII) parr 22-23.

The application of the three-pronged test having been dealt with, the discussion now proceeds to the multifaceted approach that was applied in an earlier line of Canadian cases.

\section{The Earlier, Multifaceted Test in Angiotech}

The three-pronged Lightsquared test is the more recent one for determining the COMI in Canadian law. Morawetz J's Massachusetts judgment is the door between this test and an earlier, multifaceted test in Canadian law. In Massachusetts, Morawetz J said that counsel had referred to Angiotech Pharmaceuticals Ltd. ((Re), 2011 BCSC 115 (CanLII) par 7; Massachusetts par 26). In the Supreme Court of British Columbia in Angiotech, Walker J set out ten aspects to consider in determining the COMI in Canadian law:

(1) the location where corporate decisions are made;

(2) the location of employee administrations, including human resource functions;

(3) the location of the company's marketing and communication functions;

(4) whether the enterprise is managed on a consolidated basis;

(5) the extent of integration of an enterprise's international operations;

(6) the centre of an enterprise's corporate, banking, strategic and management functions;

(7) the existence of shared management within entities and in an organisation;

(8) the location where cash management and accounting functions are overseen;

(9) the location where pricing decisions and new business development initiatives are created; and

(10) the seat of an enterprise's treasury management functions, including management of accounts receivable and accounts payable.

In Massachusetts, Morawetz J held that as the relevant Part IV of the CCAA had taken effect in September 2009, Canadian courts were not well versed in determining the COMI (Massachusetts par 19). He set out the list of ten factors and commented that these were intended to guide the interpretation of the only requirement, the COMI (Massachusetts parr $26 \& 27$ ). Some of these or other factors might be ruled more important than others (Massachusetts par 28). No single factor was decisive, and all of them might be considered in the particular circumstances of the case.

Morawetz J explained, for instance, that the place of organising or authorising finance, or the location of the debtor's main bank, would be 
important only if the bank exercised some control over the debtor (Massachusetts par 29). The location of the employees might be important if they were future creditors, but less so because protecting the employees was more a matter of protecting interested parties' rights and thus was irrelevant in determining the debtor's COMI. Further, the law of the jurisdiction governing most disputes might not be significant if the jurisdiction was not connected to the place of management or the carrying on of business. However, three aspects were usually important:

(1) the location of the debtor's headquarters or head office functions or nerve centre;

(2) the location of the debtor's management; and

(3) the location which significant creditors recognize as being the centre of the company's operations (Massachusetts par 30).

Other factors might be relevant, said the judge, but perhaps they 'should be considered to be of secondary importance and only to the extent that they relate to or support the above three factors' (Massachusetts par 31).

Morawetz J explained why it was preferable to apply this Massachusetts three-pronged test. In the Massachusetts case, the Chapter 11 debtors had begun Chapter 11 proceedings in the United States. All except three debtors were incorporated there (Massachusetts parr 5-6). Two of the Canadian debtors were registered in Ontario and the third in Nova Scotia. The issue was whether there was enough evidence to displace the rebuttable presumption regarding these Canadian debtors' registered offices in Canada (Massachusetts par 22). The head offices of all the debtors, including the Canadian ones, were in Boston (Massachusetts par 23). The debtors operated 'as an integrated North American business' in a group, and were run by all the members of the debtors' management in Boston. The Boston offices handled most of the 'human resources, accounting/finance, and other administrative functions' (Massachusetts par 23). Most of the information technology was furnished in the United States, and one of the Canadian debtors was a parent to a restaurant group operating only in the United States (Massachusetts par 23).

The applicant argued in favour of recognising the Chapter 11 proceedings as a foreign main proceeding (Massachusetts par 24). One person stated that almost half the operating premises and employees were in Canada, and that a Canadian equipment financing company had lent considerable sums to the applicant (Massachusetts par 25). But the lender company did not oppose the present application. In the circumstances, Morawetz J held that the debtors' headquarters or office functions (its 'nerve centre'), as well as the management, were in Boston (Massachusetts par 32). The important lending creditor in Canada did not oppose the relief that the applicant sought. Morawetz J thus concluded that each Chapter 11 debtor, including the Canadian ones, had its COMI in the United States. 
A summary of the longer Angiotech list of factors, and the shorter Massachusetts test, is seen in Digital Domain Media Group, Inc. (Re), 2012 BCSC 1565 (CanLII) parr $21 \& 22$. Fitzpatrick J in the Supreme Court of British Columbia held that Morawetz J in the Massachusetts test had 'identified what he considered to be the most significant factors'. Fitzpatrick $\mathrm{J}$ then also set out the revised, Lightsquared test (Digital Domain Media par 23).

Finally, it is noted that if Canadian companies intend to apply for the Canadian proceedings to be recognised under Chapter 15 of the United States Bankruptcy Code, the Canadian courts have held that the determination of the debtor's COMI is to be left to the United States court (see, for example, Cinram International Inc. (Re), 2012 ONSC 3767 (CanLII) par 42; Re iMarketing Solutions Group, 2013 ONSC 2223 (CanLII) par 30; Cline Mining Corporation (Re), 2014 ONSC 6998 (CanLII) par 52). Conversely, Chapter 11 proceedings under the United States Bankruptcy Code have been recognised as foreign proceedings under the CCAA (see Massachusetts par 13, mentioning the Babcock and Lear cases; and Magna Entertainment Corp. (Re), 2009 CanLII 9757 (ON SC); 51 CBR (5th) 82 (Ont SC)).

\section{Conclusion}

The discussion now turns to the South African position regarding the determination of the debtor's COMI. The preceding survey, in paragraph 5 , of several Canadian cases provides examples and guidelines that South African courts may find useful in determining the debtor's COMI when the CBIA comes into full force. The central determination is where this centre is located, on an objective view by third parties such as creditors. It is noted that, as in Burckhardt Reiner (see par 51 supra), an interim finding may be made that the foreign proceedings are foreign non-main proceedings, with the proviso that a later application may be made to establish that the foreign proceedings are foreign main proceedings.

The earlier, multifaceted test of ten factors (Angiotech par 7; see par 5 2 supra) provides a detailed framework for the analysis. It seems unlikely that the court would need to consider any further factors in reaching its determination. Morawetz J cautioned that, in the determination of the only requirement, the COMI, some of these ten factors might be considered to be more important than others, none being decisive, and all to be considered (Massachusetts par 28). In this regard the judge's warning about the location of where the debtor's finances are organised or authorised, or where its main bank is to be found (Massachusetts par 29), should be remembered because this factor would be important only if the debtor's bank had some measure of control over the debtor. The complicating factor would be the determination of the extent of that bank's control. Perhaps this factor would be important if the company were heavily indebted to a bank or banks, and most of the company's assets were encumbered in favour of those banks. The view of the major creditors, or a major creditor, may also be important - it is significant 
that the equipment financing company was mentioned in Massachusetts and that this lender had not opposed the application for recognition (Massachusetts par 25). It is also noteworthy that the choice of law governing most of the parties' disputes may be held not to be important if there is no link to the place where the debtor is managed or carries on business (Massachusetts par 29). This consideration would meet the expectations of local creditors in the sense that they would expect local law to apply to the resolution of disputes, rather than a foreign legal system with which they would not be familiar.

Morawetz J's views in Massachusetts (par 29) on the importance of the location of the employees are interesting. It is submitted that employees may be future creditors in the sense that their contracts of employment would normally continue to run in the event of business rescue proceedings in South African law (several of the Canadian decisions involve reorganisation -business rescue - under Chapter 11 of the United States Bankruptcy Code). But it is also significant that the interests of the employees were kept separate by Morawetz J from the determination of the debtor's COMI. In other words, the protection of one group of creditors should not impinge on the determination of the COMI. However, the facts may vary - it is conceivable that a solvent company may face a looming future debt and seek to weather the storms of this debt by resorting to business rescue; and that a sizable portion of the overall liabilities of this company may be liabilities with respect to the employees. An oversized workforce may be one of the problems that cannot be ignored.

The advantage of the multifaceted test is its variety of factors that may be considered, each to be given greater or lesser weight according to the circumstances of the case. Yet it may also be felt that in its variety lies a complication of application, and - although the facts of cases may vary - that it may take some time for a body of cases to develop in which the application of the multifaceted test may be observed and the importance given to some factors rather than others may be calibrated. In this respect, the advantage of the three-pronged test in Lightsquared is that it is simpler to apply. The Lightsquared test, as applied in the MtGox case (par 21), asks three simple questions: whether creditors can promptly ascertain the location of the debtor's COMI, whether the debtor's main assets and operations are to be found there, and whether the debtor is managed there. The three-pronged Lightsquared test, the refined version of the Massachusetts test, may, on its own, be sufficient to guide the court in determining the COMI in one country, as in MtGox. Even if the facts may be more complicated than those in MtGox and the debtor's COMI may have to be determined for each debtor which forms part of a company group, the cases of Lightsquared and Caesars demonstrate that the test is still helpful in guiding the court to determine the debtor's COMI where the rebuttable presumption of the company debtor's registered office being the COMI is displaced. 
Finally, if a South African company were to apply for the South African insolvency proceedings to be recognised under the business rescue provisions of a foreign country, the South African courts would be well advised, like their Canadian counterparts in cases such as Cinram (see par 52 supra), to decide that determining the debtor's COMI should be left to the appropriate foreign court. Conversely, it is submitted that, as in Canada (see the Massachusetts case; par 52 supra), Chapter 11 proceedings under the United States Bankruptcy Code should be recognised as foreign proceedings under the CBIA once the United States appears on the Minister's list of relevant countries.

A SMITH

University of South Africa 